\title{
Prevalence of bacterial and Candida albicans infection amongst women attending Irrua Specialist Teaching Hospital, Irrua, Nigeria
}

\author{
Isibor, J. O. ${ }^{1}$, Samuel, S. O. ${ }^{2 \star}$, Nwaham, C. I. ${ }^{3}$, Amanre I. N. ${ }^{1}$, Igbinovia, $0 .{ }^{4}$ and Akhile, A. O. ${ }^{3}$ \\ ${ }^{1}$ Department of Microbiology, Ambrose Alli University, Ekpoma, Edo State, Nigeria. \\ ${ }^{2}$ Department of Medical Microbiology, Ambrose Alli University, Ekpoma, Edo State, Nigeria. \\ ${ }^{3}$ Department of Medical Laboratory Science, Ambrose Alli University, Ekpoma, Edo State, Nigeria. \\ ${ }^{4}$ Department of Community Medicine, Ambrose Alli University, Ekpoma, Edo State, Nigeria.
}

Accepted 29 August, 2011

\begin{abstract}
Bacterial and other pathogens often infect the female genital tract causing disease in most women, sometimes with severe complications. A number of vaginal infections present with few or no symptoms and yet could still be transmissible to sexual partners of infected persons. Poor socio- economic status, lack of diagnostic facilities and shortage of effective treatment all contribute to the high incidence of sexually transmitted and reproductive tract infections. In this study we investigated mixed bacterial and Candida albicans infections in antenatal and gynecology attendees in Irrua Specialist Teaching Hospital Irrua, Edo State, Nigeria. Seventy-five high vaginal swab specimens were collected from female patients (18-49 years) attending ante-natal and gynecology clinics of the hospital. Specimens were collected from symptomatic and asymptomatic patients and were analyzed using standard microbiological methods. Wet preparations were examined microscopically for presence of white blood cells (WBC) which suggested an infection, and yeast cells. The swabs were inoculated on MacConkey, Blood, and Chocolate agars, incubated at $37^{\circ} \mathrm{C}$ for $24 \mathrm{~h}$, as well as Sabouraud Dextrose agar, incubated at room temperature for a few days. Of the seventy-five specimens analyzed, $56(74.7 \%)$ isolates were from symptomatic patients while 25 (44.6\%) were from asymptomatic patients. C. albicans was the most isolated pathogen with $35(47.7 \%)$ isolates, followed by Staphylococcus aureus with 25 (29.8\%), E. coli, $11(13.1 \%)$, Klebsiella spp, 5 (6.0\%) Enterococcus faecalis, 4(4.8\%), Proteus spp $3(3.6 \%)$ and Pseudomonas aeruginosa, $1(1.2 \%)$. This analysis revealed that candidiasis caused by $C$. albicans and infection with $S$. aureus is still the major health problems among females in this locality. The need for regular check-up at the clinics as well as personal hygiene is highly recommended in order to forestall avoidable infections.
\end{abstract}

Key words: Bacteria, Candida albicans, infection, antenatal, gynecology, attendees, Irrua, Nigeria.

\section{INTRODUCTION}

The genital tract is the portal of entry for numerous sexually and non-sexually transmitted diseases. A number of bacterial and non-bacterial infections exist that affect the female reproductive tract and cause vaginal discharge. Vaginal discharge is a common symptom in primary health care and is often the second most common gynecological problem after menstrual

\footnotetext{
*Corresponding author. E-mail: olowosamuel2003@yahoo.com.
}

disorders. Most women regard any secretion from the vagina as abnormal discharge and the first task for primary health care providers is to ascertain whether it is pathological or physiological. There are few women who complain of vaginal discharge, discomfort or odour without any objective finding (Dodson and Friedrich, 1997). Such women may be motivated by a neurotic fear of uncleanliness, guilt concerning sexual activities, or anxiety about venereal disease, whether or not sexual exposure has actually taken place.

A number of vaginal infection present with few or no 
symptoms and yet produce serious effect and can be transmissible to other people. The major factors that increase the incidence of sexually transmitted disease include the increase in promiscuity amongst people, the spread of orogenital and anogenital sexual practices in both heterosexual practices and homosexual relationships, increase in travel and migration and the wide spread use of contraceptive techniques such as contraceptive pills and intrauterine device (IUD) which, unlike the condom, do not provide a partial barrier to infection (Haukkammaa et al., 1998; Eschenbach, 1999; Sinillo et al., 2001; Hay, 1994; Geiger and Foxman, 1996). The bacterial pathogen associated with vagina infection are Neisseria gonorrhoea, E. coli, Streptococcus pyogenes, S. aureus, Treponema pallidum, E. faecalis, Clostridium perfringens, Proteus mirabilis, Klebsiella aerogenes etc. The non- bacterial pathogens include parasites such as Trichomonas vaginalis, Gardnerella vaginalis, and fungi like $C$. albicans and viruses like Herpes Simplex Virus. Others include Bacteriodes spp, Chlamydia trachomatis, Listeria monocytogenes, and $\beta$ hemolytic streptococci (Cheesbrough, 2000). The bacterial flora of the female genital tract is diverse and varied; normally aerobic lactobacilli appear in the vagina soon after birth and persist as long as the $\mathrm{pH}$ remains acidic (Cruickshank and Sharman, 1994) and more acidic $(\mathrm{pH} 4.5)$ during early month of pregnancy. The lactobacilli are suppressed by the administration of antimicrobial drugs; yeast or various bacteria increase in number and cause irritation and in most cases inflammation. After menopause, lactobacilli again diminish in number and mixed bacterial flora often include group $\beta$-hemolytic streptococci, anaerobic streptococci (peptostreptococci), Prevotella spp, Clostridia spp, G. vaginalis and Ureaplasma urealyticum.

However, studies have showed that anaerobic bacteria are more in type and number than their aerobic counterpart. The anaerobes considered to be of clinical importance are the Peptostreptococcus spp, Clostridium spp and Bacteroides spp (Barlette et al., 1999).

Moreover, several factors can be associated with increased rate of vaginal colonization by bacteria and $C$. albicans: these include pregnancy, use of high oestrogen and oral contraceptives, uncontrolled diabetes mellitus, wearing of tight-fitting synthetic underclothing, prolonged use of antibiotics which kill the good and beneficial bacteria, allowing yeast overgrowth, poor dietary habits and poor personal hygiene. The common features of vaginal infections is that at some stages, they all produce lesions at the site of infection usually in or about the external genitalia and these lesions are highly infective to the male sexual partners (Muir's, 1985; Spiegel, 1991).

In women (both pregnant and non-pregnant) $C$. albicans and $S$. aureus seem to be the most prevalent microorganisms (Kamara et al., 2000; Sobel, 1997). The high prevalence of bacteria in vaginal diseases or infection and concomitant lower genital tract infections among symptomatic and asymptomatic pregnant women and the resultant adverse pregnancy outcome associated with bacteria vaginal and Candida infection confirm the report from Govander et al. (1996). Pelvic inflammation diseases (Spiegel, 1991), sexually transmitted infection and reproductive tract infections continue to exert a tremendous health burden on women in developing countries. Poor social economic status, inadequate knowledge, lack of diagnostic facilities and shortage of effective treatment all contribute to the high incidence of sexually transmitted and reproductive tract infections (Tyadal et al., 1992; Burrow and Bueshing, 1999).

In this study we investigated mixed bacterial and $C$. albicans infections in antenatal and gynecology attendees in Irrua Specialist Teaching Hospital.

\section{MATERIALS AND METHODS}

\section{Collection of samples}

Seventy-five (75) high vaginal swab specimens were collected from both pregnant and non-pregnant patients (aged 18-49 years) attending ante-natal and gynecology clinic at Irrua Specialist Teaching Hospital, using sterile swab sticks. Specimens were collected from symptomatic and asymptomatic women. The characteristic features of the symptoms include foul smelling odour, vaginal discharge (scanty or purulent), burning sensation and pain during urination, as well as itching and irritation of the vagina. The samples were labeled and taken to the laboratory immediately for analysis.

\section{Microbiological analysis}

All the specimens were streaked on prepared MacConkey agar, Blood agar, Chocolate agar and Sabouraud dextrose agar (SDA) plates. All the plates were incubated at $37^{\circ} \mathrm{C}$ for $24 \mathrm{~h}$; the chocolate agar plates were incubated $10 \%$ carbon dioxide atmosphere at $37^{\circ} \mathrm{C}$ for $48-72 \mathrm{~h}$ in a candle jar, while SDA plates were incubated at room temperature for 3-4 days. Colonies were sub-cultured on MacConkey agar to obtain pure cultures. Colonies on blood agar were observed for haemolysis and swarming characteristics. Other colonial morphology, gram staining and biochemical reactions were used to identify the isolated organisms.

\section{Wet preparation}

About $1 \mathrm{ml}$ of normal saline was put in the tube containing the swab to cover the cotton bud, shaken and allowed to stand for some minutes. A drop of this was placed on a clean grease- free slide and was viewed with low power objectives (10 and 40x) for yeast cells, epithelial cells. Germ tube test was also carried out on suspected yeast colonies and positive colonies were sub-cultured onto corn meal agar medium for further identification by the formation of chlamydiospore by $C$. albicans.

\section{RESULTS}

Of the seventy-five (75) specimens, there was growth in 
Table 1. Distribution of bacterial and fungal isolates from female patients attending Irrua Specialist Teaching Hospital.

\begin{tabular}{lc}
\hline Microbial isolate & Number (\%) of isolates (\%) \\
\hline Candida albicans & $35(41.7)$ \\
Staphylococcus aureus & $25(29.8)$ \\
Enterococcus faecalis & $11(13.1)$ \\
Proteus spp & $5(6.0)$ \\
Klebsiella spp & $4(4.8)$ \\
Escherichia coli & $3(3.6)$ \\
Pseudomonas aeruginosa & $1(1.2)$ \\
Total & $84(100.2)$ \\
\hline
\end{tabular}

Table 2. Distribution of isolates in relation to terms of pregnancy.

\begin{tabular}{ll}
\hline Term of pregnancy & Types and number (\%) of isolates. \\
\hline $1^{\text {st }}$ trimester & Candida albicans $1(1.8 \%)$ \\
$2^{\text {nd }}$ trimester & $\begin{array}{l}\text { Candida albicans } 9(16.1 \%) \text { E. coli } 4(7.1 \%) S . \\
\text { aureus } 2(3.6 \%) \quad \text { Klebsiella spp } 1(1.8 \%) \text { and } \\
\text { Enterococcus faecalis } 1(1.8 \%)\end{array}$ \\
$3^{\text {rd }}$ trimester & $\begin{array}{l}\text { Candida albicans } 13(23.2 \%), \text { E. coli } 1(1.8 \%), S . \\
\text { aureus } 8(14.3 \%) \text { Klebsiella spp } 1(1.8 \%) \text { Proteus spp } \\
2(3.6 \%) \text { and Enterococcus faecalis } 1(1.8 \%)\end{array}$ \\
\hline
\end{tabular}

Table 3. Frequency of isolates in pregnant and non-pregnant women.

\begin{tabular}{lcc}
\hline Types of microorganisms isolated from patients & Pregnant women (\%) & Non pregnant women (\%) \\
\hline Candida albicans & $23(51.1)$ & $12(30.8)$ \\
Staphylococcus aureus & $12(26.7)$ & $13(33.3)$ \\
Enterococcus faecalis & $1(2.2)$ & $3(7.7)$ \\
Proteus spp & $2(4.4)$ & $1(2.6)$ \\
Klebsiella spp & $2(4.4)$ & $3(7.7)$ \\
Escherichia coli & $5(11.1)$ & $6(15.4)$ \\
Pseudomonas aeruginosa & $0(0.0)$ & $1(2.6)$ \\
Total & $45(99.9)$ & $39(100)$ \\
\hline
\end{tabular}

56 samples while the other samples yielded no growth. Of the 56, 24 isolates were from gynecology patients while 32 isolates were obtained from antenatal clinic attendees. The distribution of the microbial isolates from all the women in this study is shown in Table 1.C. albicans had the highest isolation rate of $35(41.7 \%)$ followed by $S$. aureus 25(29.8\%) while $P$. aeruginosa had the least isolation rate of $1(1.2 \%)$ amongst the infected patients.

Table 2 shows the distribution of isolates in relation to terms of pregnancy. The only pathogen isolated from women in their $1^{\text {st }}$ trimester was $C$. albicans with an isolation rate of $1.8 \%$. Those in their $2^{\text {nd }}$ and $3^{\text {rd }}$ trimesters of pregnancy had mixed infections with $C$. albicans and bacteria. The frequency of the infectious organisms in both pregnant and non-pregnant patients is shown in Table 3. C. albicans was the most prevalent isolate, while $P$. aeruginosa was the least isolated organism in nonpregnant women but was not isolated in pregnant women. The prevalence of isolation in symptomatic and asymptomatic ante-natal and gynaecology patients is shown in Table 4.

Table 5 shows the distribution of microbial isolates in relation to patient's age. Six bacterial genera; Escherichia, Staphylococcus, Pseudomonas, Klebsiella, Proteus and Enterococcus were isolated, while the yeast, C. albicans, was the only fungus isolated from the samples. 
Table 4. Distribution of isolates in symptomatic and asymptomatic patients.

\begin{tabular}{lcc}
\hline Patients & No (\%) of symptomatic patients & No (\%) of asymptomatic patients \\
\hline Antenatal patients & $13(23.2)$ & $17(30.4)$ \\
Gynecology patients & $18(32.1)$ & $8(14.3)$ \\
\hline
\end{tabular}

Table 5. Distribution of isolates according to age of parents.

\begin{tabular}{|c|c|c|}
\hline Age & Microbial isolate & $\mathrm{No}(\%)$ of isolate \\
\hline \multirow[t]{3}{*}{ 15-20 (3 patients) } & Candida albicans & $1(1.8)$ \\
\hline & Staphylococcus aureus & $1(1.8)$ \\
\hline & Enterococcus faecalis & $1(1.8)$ \\
\hline \multirow[t]{3}{*}{ 21-25 (13 patients) } & Candida albicans & $11(19.7)$ \\
\hline & S. aureus & $7(12.5)$ \\
\hline & E. coli & $3(5.4)$ \\
\hline \multirow[t]{6}{*}{ 26-30 (18 patients) } & Candida albicans & $12(21.2)$ \\
\hline & S. aureus & $5(8.7)$ \\
\hline & E. coli & $4(7.1)$ \\
\hline & Proteus spp & $2(3.6)$ \\
\hline & Klebsiella spp & $1(1.8)$ \\
\hline & Enterococcus faecalis & $1(1.8)$ \\
\hline \multirow[t]{7}{*}{ 31-35 (11 patients) } & Candida albicans & $7(10.7)$ \\
\hline & S. aureus & $5(8.7)$ \\
\hline & E. coli & $1(1.8)$ \\
\hline & Enterococcus faecalis & $1(1.8)$ \\
\hline & Klebsiella spp & $2(3.6)$ \\
\hline & Proteus spp & $1(1.8)$ \\
\hline & Pseudomonas aeruginosa & $1(1.8)$ \\
\hline \multirow[t]{4}{*}{ 36-40 (6 patients) } & Candida albicans & $1(1.8)$ \\
\hline & S. aureus & $4(7.1)$ \\
\hline & Klebsiella spp & $1(1.8)$ \\
\hline & E. coli & $1(1.8)$ \\
\hline \multirow[t]{4}{*}{ 41-45 (4 patients) } & Candida albicans & $1(1.8)$ \\
\hline & Staphylococcus aureus & $4(7.1)$ \\
\hline & E. coli & $1(1.8)$ \\
\hline & Klebsiella spp & $1(1.8)$ \\
\hline \multirow[t]{2}{*}{ 46-49 (1 patient) } & E. coli & $1(1.8)$ \\
\hline & S. aureus & $1(1.8)$ \\
\hline
\end{tabular}

\section{DISCUSSION}

The results revealed that several species of microbes are responsible for vaginal infection among females. Vaginal discharge is one of most frequent gynecological problems encountered in females especially during their reproductive stage. Of the organisms isolated, $C$. albicans had the highest isolation rate (41.7\%), followed by $S$. aureus $(29.8 \%)$. P. aeruginosa had the least isolation rate of $1.2 \%$ (Table 1). The high prevalent rate of $C$. albicans observed in this study is an indication that C. albicans is becoming a leading etiology of the reproductive tract infections in women of child bearing age. 
As shown in Table 3, it can be deduced that the high incidence rate of $C$. albicans in pregnant women 23 (51.1\%) compared to non-pregnant women 12 (30.8\%) could be due to increased oestrogen content, glycosuria in the acidity of the vagina due to rich glycogen content of the vaginal mucosa thereby providing an ample supply of utilizable sugar that favor the growth of $C$. albicans during pregnancy. This high incidence of candidiasis among women, and especially pregnant ones, supports the earlier studies of Eschenbach et al. (1999), Ohm and Salask (1995), Hammill (2000) and Chandra et al. (1990). The highest rate of candidiasis $(23.2 \%)$ was found amongst women in their third trimester of pregnancy, as against the second trimester (16.1\%) and the first (1.8\%) (Table 2). This result may be due to an increase in the fetal demand for nutrients as pregnancy progresses, leading to an increase in hormonal secretions and then immuno-suppression of the mother's health. Moreover, the high incidence of candidiasis among the age range of 26-30 years (Table 5) could be due to the higher oestrogen content of the vaginal epithelia (Sobel, 1997). Also the age range of between 21-35 years constitute the sexually active period of most women. Of the 35 patients with candidiasis, $18(51.4 \%)$ were symptomatic while 17 $(48.6 \%)$ were asymptomatic (Table 4). It must be recognized that the unnoticed asymptomatic infection caused by $C$. albicans could likely lead to other severe complications. Therefore, the diagnosis of asymptomatic infection especially in pregnant women is of great importance.

The involvement of $S$. aureus in vaginal discharge or infection of the female genital tract has been an issue in the microbiology of vaginal infections. As shown in the tables above, its occurrence was the highest among other bacteria isolated from the patients. The presence of $S$. aureus along side with other bacteria such as $E$. coli, E. faecalis, Klebsiella spp, Proteus spp and $P$. aeruginosa may be attributed to immune status of the individual, lack of personal hygiene regarding the proximity of the vagina to the urethral tract from where these bacterial species may readily gain access into the vagina. Faecal organisms from the anus could also be introduced into the vagina during cleaning by using the ascending route (back to front) instead of the descending route (front to back).

\section{Conclusion}

Among the organisms responsible for female genital discharge $C$. albicans was found to be the highest pathogen isolated and it cut across all the clinical cases investigated during this study. More work should be encouraged in this direction to reduce the incidence of female genital discharge, especially on the vaginal ecosystem, since it is believed that a balanced ecosystem with the appropriate proportion of organisms such as Lactobacillus spp helps to keep the female genitalia in a healthy condition (Fisher, 1993; Geiger and Foxman, 1996). All pregnant females should go for regular routine check- up. Symposia should be organized regularly to enlighten young women on the importance of personal hygiene, the use of condom for safe sexual activities, appropriate use of contraceptive pills and antibacterial drugs as well as the proper choice of cloths to avoid wearing tight fitting underpants that allow the overgrowth of pathogenic organisms like $C$. albicans.

\section{REFERENCES}

Barlette JJ, Berg AO, Heidrich FE (1999). Clinical comparism of microscopic and culture techniques in the diagnosis of vaginal infections. J. Fam. Prac., 2(3): 24-33.

Burrow RC, Bueshing UJ (1999). Bacterial vaginosis in virgins and sexually active females: Evidence against exclusive sexual transmission. J. Obstet. Gynecol., 8(5): 97 -99.

Cheesbrough M (2000). Microbiological test in; District laboratory practice for tropical countries part 2, Cambridge Low Price Edition, Cambridge University Press; pp. 69-71.

Cruickshank DR, Sharman PO (1994). Epidemiology and outcomes associated with moderate to heavy Candida colonization. Am. J. Intern. Med., 149(78): 33-35.

Dodson MG, Friedrich EG (1997). Psychosomatic vulvovaginitis. J. Obstet. Gynecol., 51(23): 98.

Eschenbach DA, Hillier S, Critchoer C (1999). Diagnosis and Clinical manifestation of bacterial vaginosis. J. Obstet. Gynecol., 16 (8): 178.

Fisher B (1993). The Epidemiology of vulvovaginal candidiasis, risk factors AMF Public Health., 80: 329-331.

Geiger AM, Foxman B (1996). Risk factors for vulvovaginal candidiasis; A case control study among university students. J. Epiderm., 7(10): 23-25.

Hammill HA (2000). Trichomonas vaginalis. J. Obstet. Gynecol., 16(39): 234-236.

Haukkammaa N, Stranden P, Jousimies- Somer H, Stitonen A (1998). Bacterial flora in the vagina. J. Obstet. Gynecol., 55 (7): 520-521.

Hay GB (1994). The microbiology of bacterial vaginosis. J. Obstet. Gynecol., 234 (4): 330-332.

Kamara P, Patrick N, Weiss H (2000). Vaginal infections in pregnant women in Jamaica: Prevalence and risk factors. Int. J. Std. AIDS., 8(12): 516-520.

Muir's RP (1985). Sexually transmitted diseases, In: Textbook of pathology. $8^{\text {th }}$ Ed; Lange medical books, McGraw-Hill Companies, International Edition: pp. 366-368.

Ohm DD, Salask NJ (1995). Anaerobes and septic abortion. Afr. J. Med. Sci., 6(15): 66-68.

Sinillo JD, Faro S, Force RW, Foxman B, Ledger WJ, Nyirjesy PR (2001). Vulvovaginal Candidiasis; epidemiology, diagnostic and therapeutic consideration. J.Obstet. Gynecol., 178(53): 37-42.

Sobel JD (1997). Vaginitis. N. Engl. J. Med., 337(18): 234-236.

Spiegel CA (1991). Bacterial vaginosis. Clin. Microbiol. Rev., 4: 485502.

Tyadal SP, Zaaijamann JD, Kent HL (1992). An unusual vaginal foreign body. Afr. Med., 61(33): 108-110. 